Research Article

\title{
Experimental Investigation on Asphalt Binders Ageing Behavior and Rejuvenating Feasibility in Multicycle Repeated Ageing and Recycling
}

\author{
Yihua Nie $\mathbb{D}^{1},{ }^{1,2}$ Shiheng Sun, ${ }^{1}$ Yajun Ou, ${ }^{1}$ Chenyang Zhou, ${ }^{1}$ and Kunli Mao $\mathbb{D}^{3}$ \\ ${ }^{1}$ School of Civil Engineering, Hunan University of Science and Technology, Xiangtan 411201, China \\ ${ }^{2}$ Key Laboratory of Road Structure and Material of Ministry of Transport (Changsha), \\ Changsha University of Science \& Technology, Changsha 410114, China \\ ${ }^{3}$ Hunan Communication Polytechnic, Changsha 410132, China \\ Correspondence should be addressed to Kunli Mao; gcjxzk@163.com
}

Received 4 November 2017; Accepted 1 March 2018; Published 5 April 2018

Academic Editor: Ashkan Vaziri

Copyright (c) 2018 Yihua Nie et al. This is an open access article distributed under the Creative Commons Attribution License, which permits unrestricted use, distribution, and reproduction in any medium, provided the original work is properly cited.

\begin{abstract}
Multicycle repeated utilization of reclaimed asphalt pavement (RAP) is a quite recent development of sustainable pavement materials technology. To investigate ageing rules and recycling possibility of asphalt binders in repeatedly used asphalt mixture, virgin asphalt $\mathrm{AH}-70$ samples were heated by the rolling thin film oven test (RTFOT) at $163^{\circ} \mathrm{C}$, respectively, for $40,85,180,240$, and 300 minutes to simulate different ageing degrees, and then the aged ones were rejuvenated by adding a self-made rejuvenator. This ageing and recycling process was repeated altogether for 5 cycles to simulate repeated use of RAP binders. In repeated recycling, rejuvenator contents for different cycle numbers or ageing durations were not the same, and the optimum ones were initially estimated by an empirical formula and finally obtained by comparative tests. Empirical rheological tests and the infrared spectral (IR) analysis were done before and after each cycle of recycling. Results indicate that for impact on deterioration of asphalt binders, ageing time is more important than cycle number. Meanwhile, the asphalt after multicycle repeated ageing and recycling can be restored to the empirical rheological indices level of the virgin asphalt and meet specifications requirements.
\end{abstract}

\section{Introduction}

The amount of global reclaimed asphalt pavement (RAP) increases every year because of maintenance or rehabilitation of more and more asphalt concrete pavements reaching their service life. With the increase of the environmental awareness of people and the cost for petroleum-based asphalt as the binder of asphalt concrete, use of RAP has been the common construction practice for several decades in some countries or areas, such as the USA, Japan, and Europe. A recent survey shows that in the USA, the average percentage of RAP used in asphalt mixtures has increased from 15.6 percent in 2009 to 20.5 percent in 2016, and many U.S. state agency specifications allow up to 30 percent [1]. Across Europe, many studies have been conducted with the objective of promoting RAP contents in asphalt mixtures as much as $60 \%$, and especially in Netherlands, one challenge is to produce base course mixtures even with RAP contents $70 \%[2,3]$. In Japan, present recycling ratio of recycled asphalt pavement, which has been recommended to utilize by law since 2000 , is close to $100 \%$ [4].

Deterioration characteristics of aged asphalt binders in RAP may stiffen the mixture and cause cracking failure of the pavement if not treated carefully [5-9]. To stimulate the reasonable use of RAP, it is urgent to research the ageing behavior of asphalt under high temperature and oxidative condition and suitable rejuvenator added to the aged asphalt with appropriate dosage. In recent years, many researchers have investigated ageing behavior based on macro- and microperformance by simulating long-term ageing in laboratory [10]. Optimum contents and effects of rejuvenators on performance-based properties of recycled asphalt binders have been studied [11-13]. Analysis of binders' ageing rate shows that selecting the proper rejuvenator can extend the binders' service life up to 10 years more than that softened by a less 
TABLE 1: Properties of virgin asphalt (AH-70).

\begin{tabular}{lccc}
\hline Property & Penetration $\left(25^{\circ} \mathrm{C}, 0.1 \mathrm{~mm}\right)$ & Softening point $\left({ }^{\circ} \mathrm{C}\right)$ & Ductility $\left(15^{\circ} \mathrm{C}, \mathrm{cm}\right)$ \\
\hline Value & 66.1 & 56.0 & 150.0 \\
\hline
\end{tabular}

effective rejuvenator [14]. The focus has been mainly on the asphalt after once ageing and recycling; however, the fact is that certain RAP materials have already experienced multicycle repeated ageing and recycling during the past decades. Recently, some researchers began to concern properties changes and recovering effects of the bitumen or asphalt mixture after two or three cycles of ageing and recycling. In the European project Re-Road-End of Life Strategies of Asphalt Pavements [15], a multiple recycling study was made to investigate the effect of recycling a mixture containing polymer modified bitumen for 3 recycling cycles on the performance of the resulting mixtures. The result shows that the commonly used hot recycling process can be repeated three times considering moderate contents (50\%) of RAP in new hot mixtures. Luo and Ji [16] investigated the properties of the common asphalt (60-80 penetration) and SBS modified asphalt after two cycles of ageing and recycling by adding rejuvenator and analyzed their antiageing capacities. Montepara et al. [17] evaluated the possibility of reusing three different cold recycling mixtures composed by the same RAP as aggregate base but different asphalt emulsions as added binders to obtain a new secondgeneration material. However, ageing behavior and rejuvenating effects after multicycle (3 cycles more) ageing and recycling process are still unclear and need further research.

In this study, the Rolling Thin Film Oven Test (RTFOT) was adopted to simulate various degrees of long-term ageing effect of the common virgin asphalt by changing its duration in the oven. Commonly the RTFOT is applied to simulate asphalt's short-term ageing, and the Pressure Ageing Vessel (PAV) test is used for long-term ageing simulation. However, research shows the RTFOT with expanding time or higher temperatures is also applicable for long-term ageing simulation with the advantages such as less experimental time, simpler operation, and lower equipment price affordable for the user compared with the PAV at $100^{\circ} \mathrm{C}$ $[18,19]$. Our self-made rejuvenating agent was added to the asphalt at a certain content after each ageing cycle, and empirical rheological indices of asphalt, including penetration, softening point, and ductility, were measured before and after each recycling cycle. Chemical changes of asphalt before and after each recycling cycle were assessed by Infrared Spectral (IR) analysis. In this study, five groups of the same common asphalt, respectively, experienced five-cycle ageing by RTFOT at $163^{\circ} \mathrm{C}$ with respective ageing duration and recycling by adding rejuvenator at certain content. Empirical rheological indices changing rules with duration and cycle number were analyzed and feasibility of multicycle recycling of pavement asphalt was discussed.

\section{Experimental Program}

2.1. Materials. The AH-70 (60-80 penetration) asphalt binder from China widely used in Chinese highway construction was
TABLE 2: Properties of rejuvenator.

\begin{tabular}{lc}
\hline Property & Value \\
\hline $\begin{array}{l}\text { Proportion by weight of three components in } \\
\text { rejuvenator (epoxy resin : vegetable oil : new asphalt }\end{array}$ & $4: 6: 90$ \\
$\begin{array}{l}\text { AH-90) } \\
\text { Penetration }\left(25^{\circ} \mathrm{C}, 0.1 \mathrm{~mm}\right) \text { of rejuvenator }\end{array}$ & 186.1 \\
$\begin{array}{l}\text { Penetration }\left(25^{\circ} \mathrm{C}, 0.1 \mathrm{~mm}\right) \text { of new asphalt AH-90 in } \\
\text { rejuvenator }\end{array}$ & 88.8 \\
$\begin{array}{l}\text { Softening point }\left({ }^{\circ} \mathrm{C}\right) \text { of new asphalt AH-90 in } \\
\text { rejuvenator }\end{array}$ & 56.0 \\
$\begin{array}{l}\text { Ductility }\left(15^{\circ} \mathrm{C}, \mathrm{cm}\right) \text { of new asphalt AH-90 in } \\
\text { rejuvenator }\end{array}$ & 150.0 \\
\hline
\end{tabular}

adopted as the virgin asphalt in this research. The self-made rejuvenating agent added to the aged asphalt was composed of epoxy resin, vegetable oil, and softer new asphalt of type AH-90 (80-100 penetration) at certain proportion which were preheated and blended fully. In Europe, RAP recycling can be realized by adding a soft enough virgin binder, the penetration grade of which is normally determined by the log penetration rule [20], and in many cases, at not very high RAP contents, real rejuvenator is not necessary. However, study has shown that asphalt rejuvenators can allow more recycled materials to be incorporated in asphalt mixtures than soft binders alone [21]. In this research, to promote multicycle recycling effectiveness and feasibility, soft new asphalt and real rejuvenator such as epoxy resin and vegetable oil, which we totally call rejuvenator, were added into the aged asphalt. Tables 1 and 2, respectively, show related properties of the virgin asphalt and the rejuvenator meeting the requirements of current Chinese specifications $[22,23]$.

2.2. Multicycle Ageing and Recycling Method. The virgin asphalt was divided into six groups (groups $0 \sim 5$ ). The six batches of sample were aged using the Rolling Thin Film Oven (RTFO) [24] at $163^{\circ} \mathrm{C}$, respectively, for 0 (i.e., the virgin asphalt), 40, 85, 180, 240, and 300 minutes to simulate different asphalt ageing degrees varying from short-term ageing in asphalt mixture production and paving to longterm ageing effect of pavement asphalt. Related empirical rheological indices and chemical changes of the aged asphalt binder were measured after ageing.

The rejuvenator was added to the aged asphalt samples at different contents by weight according to the respective ageing duration and cycle number (e.g., for group 1 asphalt sample, though the second and the third cycle ageing durations are the same $40 \mathrm{~min}$, rejuvenator contents for these two cycles recycling may be different). In detail, see the section of rejuvenator dosage determination. The aged asphalt and the rejuvenator were blended at $120^{\circ} \mathrm{C}$ and stirred by a small high-speed shearing mixer for 30 minutes at speed $10,000 \mathrm{rpm}$ to ensure fully mixing. 


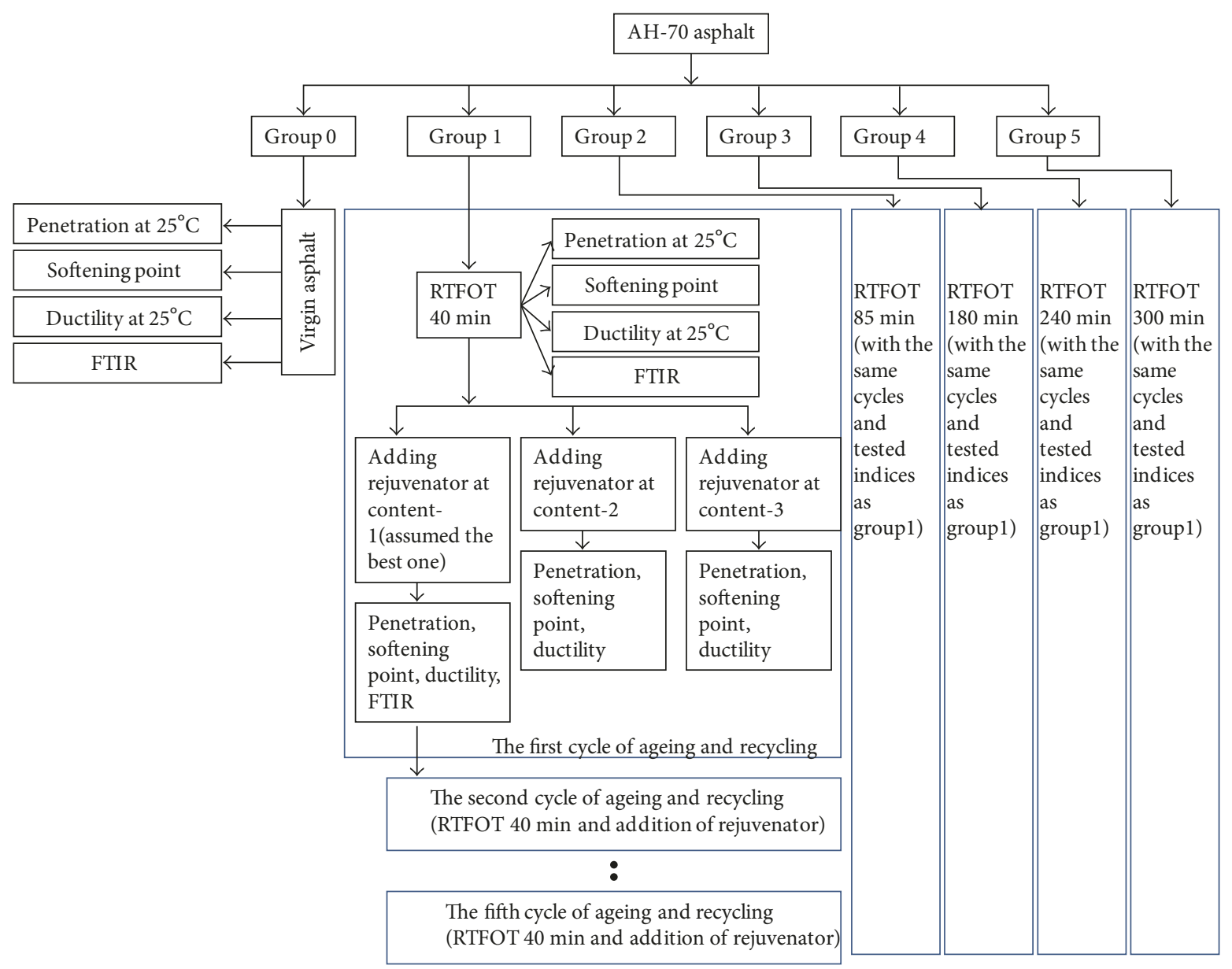

Figure 1: The experimental plan.

For group 1, during the first cycle of ageing and recycling, the virgin asphalt sample was aged for $40 \mathrm{~min}$ by RTFOT at $163^{\circ} \mathrm{C}$. The first aged asphalt is recycled by adding the rejuvenator at certain content (resp., adding the rejuvenator at three different contents for indices comparative tests and obtaining the best one) to recover original level. The first recycled asphalt at the best content then underwent the second ageing and recycling, which was the same process as the first cycle including the same ageing duration $40 \mathrm{~min}$. This process has been repeated altogether for five cycles. For groups $2 \sim 5$, the multicycle ageing and recycling process was the same as group 1, except for changing the ageing duration respectively for $85,180,240$, and 300 minutes. The experimental plan is given in Figure 1.

2.3. Empirical Rheological Tests. In this study, key empirical rheological indices of the asphalt binder such as penetration, softening point, and ductility were measured after each ageing or recycling cycle. Penetration at $25^{\circ} \mathrm{C}$ of the aged asphalt or recycled in each cycle was obtained following present Chinese test specifications [25]. Softening point was measured following standard ball and ring testing method [26]. Ductility test at $15^{\circ} \mathrm{C}$ was conducted strictly according to the procedure stipulated in specifications [27].
To avoid additional ageing, preparation of specimens for tests should be done with subprocesses such as preheating, heating, and molding completed one time. Molding temperature of specimens should be controlled at $135 \sim 145^{\circ} \mathrm{C}$.

2.4. Infrared Spectral Analysis. Fourier Transform Infrared Spectroscopy (FTIR) (Nicolet 6700, Thermo Fisher Scientific, USA) was used to investigate chemical changes of asphalt binders. The FTIR parameters were revolution $4 \mathrm{~cm}^{-1}$, scan number 32 times, and test range $4000 \sim 400 \mathrm{~cm}^{-1}$. The instrument was installed in air-conditioned room $\left(17 \sim 27^{\circ} \mathrm{C}\right)$.

The asphalt sample was blended with potassium bromide $(\mathrm{KBr})$ at asphalt/KBr ratio about $1: 3$, grinded fully, and finally tabulated to circularity about $1 \mathrm{~mm}$ thick. Immediately, the prepared circular specimen was put into FTIR and scanned by infrared light. The infrared spectra of the asphalt binder were obtained at a $4 \mathrm{~cm}^{-1}$ revolution.

2.5. Rejuvenator Dosage Determination. In this paper, the self-made rejuvenator composed of epoxy resin, vegetable oil, and new asphalt was adopted. For aged asphalt samples with different ageing time periods or ageing cycle numbers, rejuvenator contents were selected as below. The rejuvenator content was firstly estimated by empirical equation (1), 
TABLE 3: Results of comparative tests of group 4 (e.g., the 4 th cycle).

\begin{tabular}{lcccc}
\hline Index & Asphalt after & Virgin asphalt & \multicolumn{3}{c}{ Rejuvenated asphalt (rejuvenator content) } \\
& 240 min ageing & $52 \%$ & $55 \%$ & $58 \%$ \\
\hline Penetration $\left(25^{\circ} \mathrm{C}\right.$, & 24.9 & 66.1 & 58.3 & 62.2 \\
$0.1 \mathrm{~mm})$ & 75.7 & 56.0 & 62.4 & 58.5 \\
Softening point $\left({ }^{\circ} \mathrm{C}\right)$ & 6.8 & 150.0 & 125.6 & 57.8 \\
Ductility $\left(15^{\circ} \mathrm{C}, \mathrm{cm}\right)$ & & & 130.4 \\
\hline
\end{tabular}

which is converted from viscosity blending charts and revised based on a great number of related asphalt rejuvenating experimental data [28]. Equation (1) shows how the penetration of the rejuvenated asphalt blended by the old asphalt and the rejuvenator is calculated:

$$
P_{\mathrm{r}}=X^{a}\left(\lg P_{\mathrm{a}}-C\right)+(1-X)^{a}\left(\lg P_{\mathrm{o}}-C\right)+C,
$$

where $P_{\mathrm{r}}$ is the expected penetration of the rejuvenated asphalt $(0.1 \mathrm{~mm}), X$ is the rejuvenator content by weight (decimal), $a$ is the index for deviation (selected to be 1.02 for the rejuvenator used in this paper), $P_{\mathrm{a}}$ is the penetration of the added rejuvenator $(0.1 \mathrm{~mm}), P_{\mathrm{o}}$ is the penetration of the old asphalt $(0.1 \mathrm{~mm})$, and $C$ is a constant, which is equal to 4.6569 .

The estimated value of the rejuvenator content calculated from (1) was revised for three different ones in certain range, and the rejuvenator was added respectively at these three contents for indices comparative tests. According to the tests result, the best one was obtained, and the recycled asphalt at this content was used for FTIR test and the next cycle ageing and recycling. Table 3 shows related empirical rheological indices of the aged and rejuvenated asphalt samples of group 4 (e.g., the 4 th cycle), respectively, at rejuvenator contents $52 \%, 55 \%$, and $58 \%$. From Table 3 , it is found that the optimum rejuvenator content of the asphalt sample group 4 in the 4 th recycling cycle after 240 min ageing is 55\% with the best rejuvenating effect.

\section{Results and Discussion}

3.1. Asphalt Empirical Rheological Indices Changes after Multicycle Ageing and Recycling Process. Figures 2-4, respectively, show results of penetration at $25^{\circ} \mathrm{C}$, softening point, and ductility at $15^{\circ} \mathrm{C}$ after different ageing time periods for each ageing cycle. It is firstly found that at ageing cycles' indices exhibit an exponential function relationship with ageing time, which is consistent with the first-order reaction kinetic model of asphalt ageing [29, 30].

In the asphalt ageing process, oxidation and condensation reactions decrease the aromatic constituent concentration and adversely increase the asphaltene content. The first-order reaction means that chemical reaction rate is calculated as follows:

$$
\frac{-d C}{d t}=k C
$$

where $C$ is the reactant concentration, $t$ is the ageing time, and $k$ is a constant. By integrating on both sides of (2) and assuming related macroperformance indices directly or inversely proportional to the reactant concentration $[31,32]$, relationship between empirical rheological indices and ageing time is expressed uniformly as

$$
M=A e^{B t},
$$

where $M$ represents penetration at $25^{\circ} \mathrm{C}$ and softening point or ductility at $15^{\circ} \mathrm{C}, t$ is the ageing time (min) and both $A$ and $B$ are constants ( $B$ is negative for penetration or ductility and positive for softening point). Exponential regression equations in Figures 2-4 show that the absolute value of ageing rate coefficient $B$ increases with ageing cycle number.

Based on theoretical analysis and experimental investigation, it is concluded that related empirical rheological indices show an exponential deterioration trend with ageing time in any ageing cycle, and the deterioration rate relatively becomes faster with ageing cycle number increasing.

Figures 5-7, respectively, present changing rule of penetration at $25^{\circ} \mathrm{C}$ and softening point and ductility at $15^{\circ} \mathrm{C}$ of the asphalt samples with ageing cycle number for the same ageing time period. It is found that empirical rheological indices worsen with ageing cycle number, but the impact of ageing cycle number on empirical rheological indices especially penetration at $25^{\circ} \mathrm{C}$ is relatively less than that of ageing time. For penetration at $25^{\circ} \mathrm{C}$ in Figure 5 , the maximum decreases appear between the $3 \mathrm{rd}$ and the 4 th cycles without exception. However, for softening point in Figure 6 or ductility at $15^{\circ} \mathrm{C}$ in Figure 7 , the maximum changes occur between the 1 st and the 2 nd cycles with the exception of $85 \mathrm{~min}$ or $40 \mathrm{~min}$.

3.2. Infrared Spectral Analysis Results and Discussion. Infrared spectral analysis is one of the most widely used methods in the study of chemical structure of polymers. This technique was adopted to obtain the characteristics of the functional groups in asphalt binders by observing the changes in the absorption peaks of the main functional groups and get the further understanding of the asphalt multicycle ageing and recycling process based on chemical changes.

Figure 8 shows the infrared spectra of the virgin asphalt and the asphalt in five ageing cycles for $180 \mathrm{~min}$, and Figure 9 presents those of the virgin asphalt and the asphalt in five recycling cycles for $180 \mathrm{~min}$. By comparing spectra of the asphalt in ageing or recycling cycles with those of the virgin asphalt, strong absorption peaks are observed at the same wavenumber but with relatively weaker or stronger intensity, such as the strongest bands with peak at $2923 \mathrm{~cm}^{-1}$ (shoulder peak at $2851 \mathrm{~cm}^{-1}$ ), and the second strongest bands with peak at $1455 \mathrm{~cm}^{-1}$ (shoulder peak at $1375 \mathrm{~cm}^{-1}$ and neighbor peak at $\left.1610 \mathrm{~cm}^{-1}\right)$. In the strongest bands, absorption peaks correspond to $\mathrm{C}-\mathrm{H}$ stretching vibration in the alkanes of the 


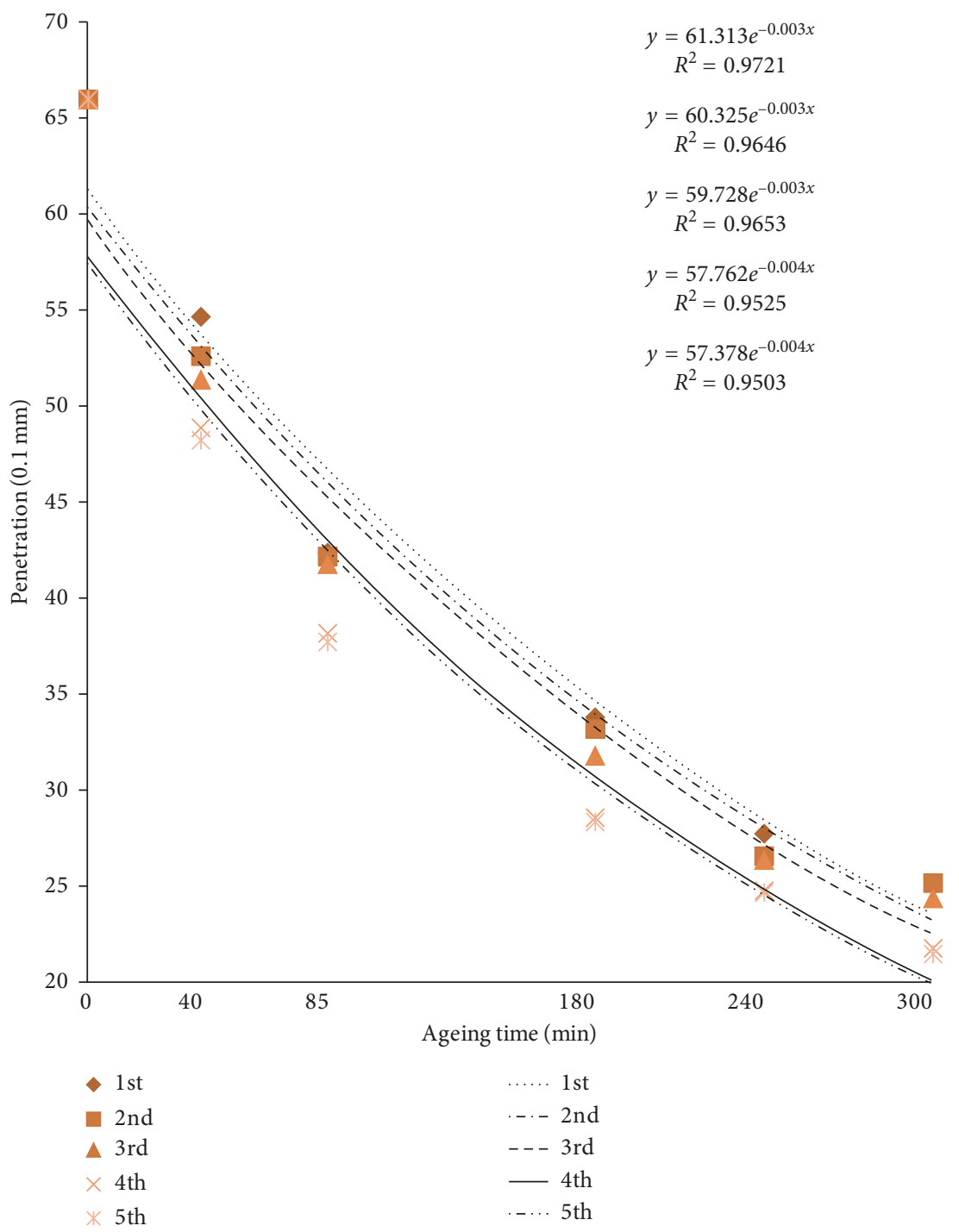

Figure 2: Penetration at $25^{\circ} \mathrm{C}$ versus ageing time for different ageing cycle numbers.

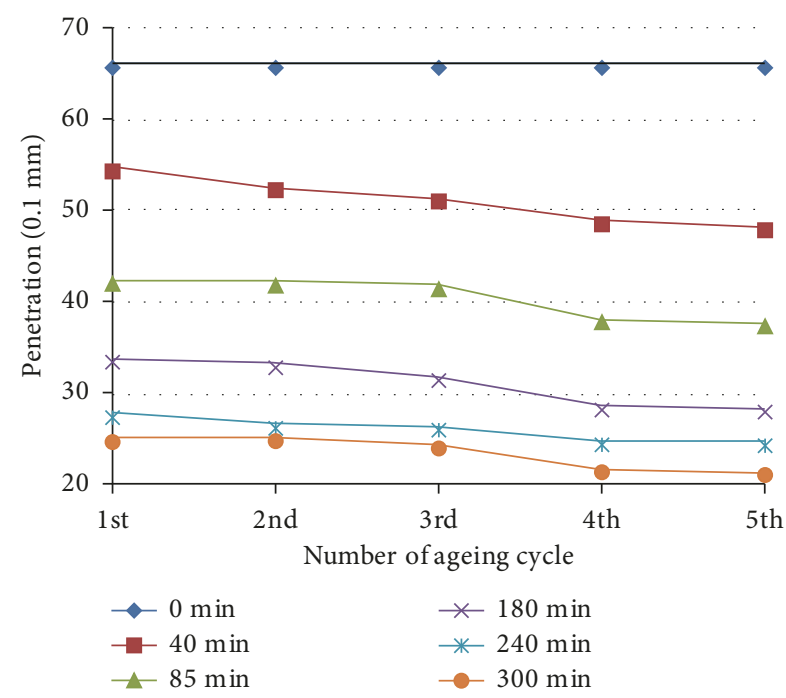

FIGURE 3: Softening point versus ageing time for different ageing cycle numbers. asphalt. In the second strongest bands, absorption peak at $1610 \mathrm{~cm}^{-1}$ is caused by $\mathrm{C}=\mathrm{C}$ skeleton vibration in the aromatic ring of the asphalt and those at $1455 \mathrm{~cm}^{-1}$ and $1375 \mathrm{~cm}^{-1}$ are caused by $\mathrm{C}-\mathrm{H}$ bending vibration in the alkanes of the asphalt.

New absorption peak appears at $1720 \mathrm{~cm}^{-1}$ on the spectral curve of asphalt in each ageing or recycling cycle, owing to carbonyl group produced in the aged asphalt. The carbonyl group exists in products of asphalt oxidation such as aldehydes, ketones, and esters [33]. At $1030 \mathrm{~cm}^{-1}$ on all spectral curves including the virgin asphalt, absorption peak intensity increases with the cycle number. This absorption peak is related with sulfoxide group formed by sulfur element in the asphalt under sustained heat and oxygen condition.

In the asphalt ageing process, polar functional groups such as carbonyl and sulfoxide produced in chemical reaction accelerate intermolecular interactions and lead to constituent changes and empirical rheological indices deterioration of the asphalt. However, asphalt recycling process is the reverse and physical one, which by adding fit 


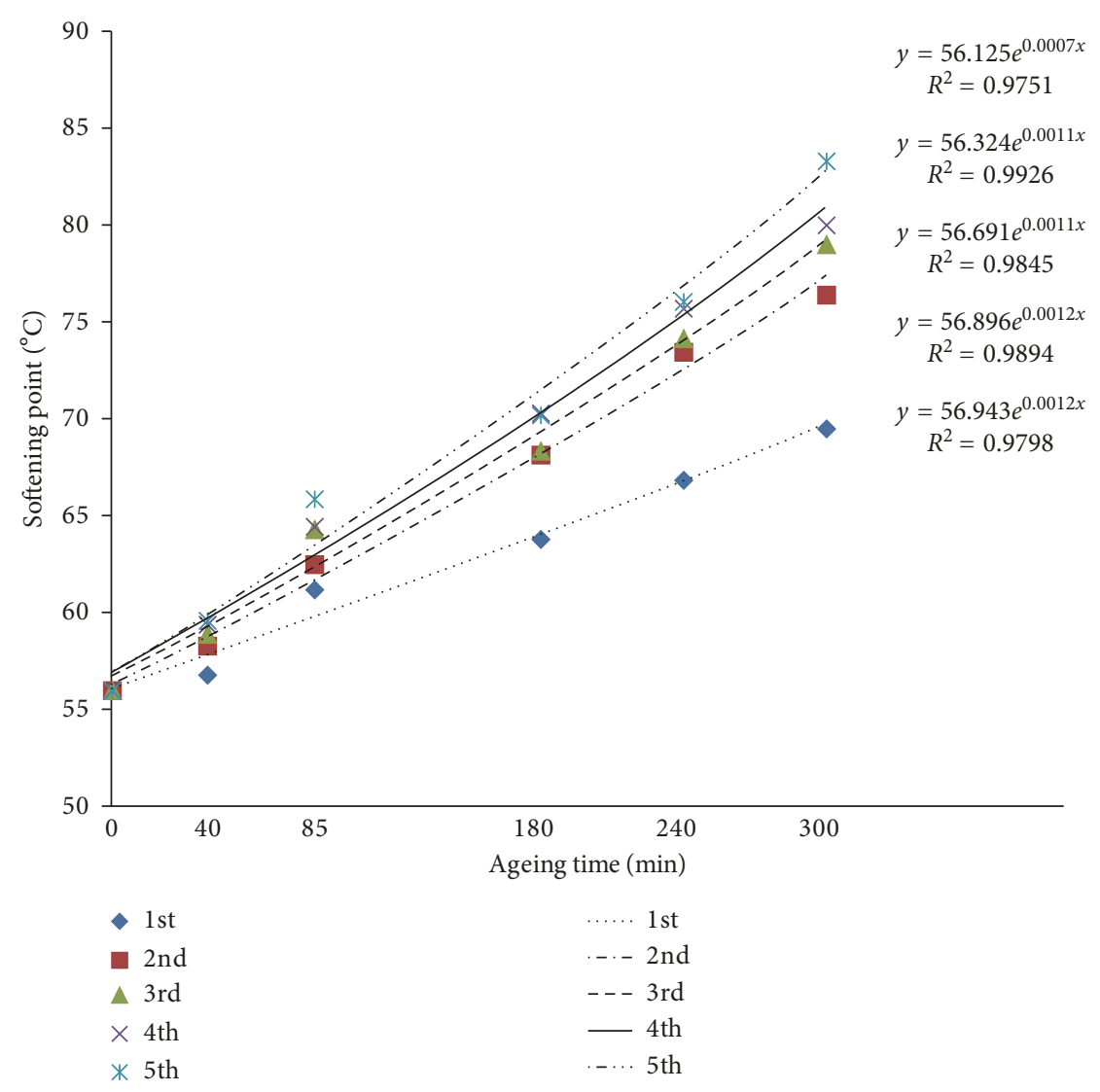

Figure 4: Ductility at $15^{\circ} \mathrm{C}$ versus ageing time for different ageing cycle numbers.

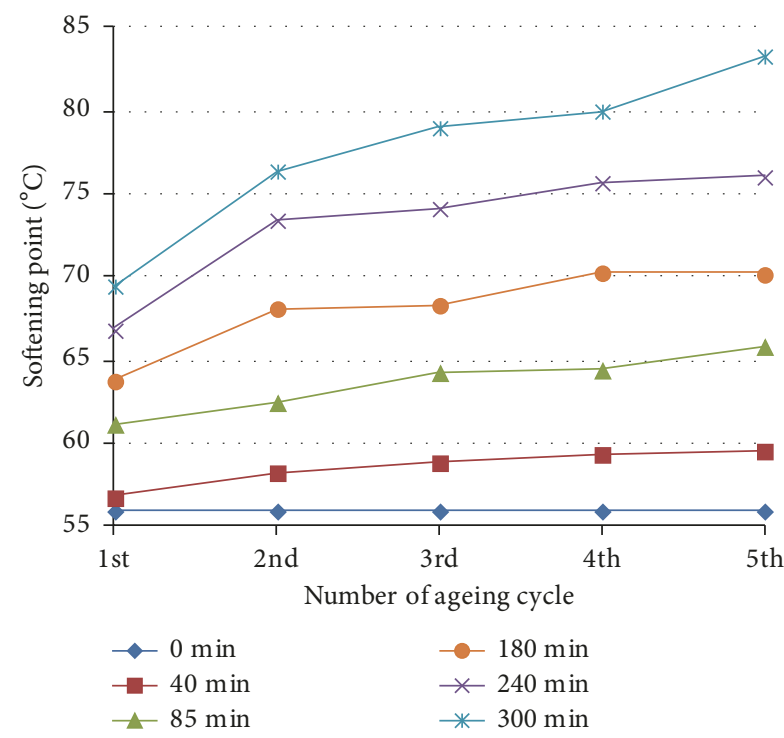

Figure 5: Penetration at $25^{\circ} \mathrm{C}$ against ageing cycle number for different ageing time periods.

rejuvenator reduces the polar functional groups contents, adjusts the component, and realizes empirical rheological indices recovery of the asphalt.

To further investigate ageing behavior and rejuvenating effect of asphalt in multicycle ageing and recycling process, quantitative calculation is necessary. In this study, two chemical indices including carbonyl index (CI) and sulfoxide index (SI) are calculated to evaluate the asphalt ageing degree. Taking into consideration that thickness deviation of IR specimen tablet will influence transmittance and absorption peak intensity, relative values are adopted. The carbonyl index is the ratio of the absorption peak area near $1720 \mathrm{~cm}^{-1}$ caused by carbonyl group to that near $1455 \mathrm{~cm}^{-1}$ on the same spectral curve caused by saturated $\mathrm{C}-\mathrm{H}$ bending vibration. The sulfoxide index is the ratio of the absorption peak area near $1030 \mathrm{~cm}^{-1}$ caused by sulfoxide group to that near $1455 \mathrm{~cm}^{-1}$. Table 4 shows CI and SI results of the virgin asphalt and the asphalt in each ageing or recycling cycle for $180 \mathrm{~min}$.

From results in Table 4, CI and SI increase with ageing cycle number, indicating that some ageing damage accumulates and ageing degree is related with ageing cycle number. It corresponds to the relationship between empirical rheological indices and ageing cycle number. CI in the 3 rd ageing cycle is 0.156 , whereas CI in the 4 th ageing cycle is 0.307 , which corresponds to an increase of approximately $100 \%$. SI also increases about $100 \%$ between the $3 \mathrm{rd}$ and the 4 th ageing cycles. The maximum change of CI or SI occurs between the same two cycles with those of penetration, which indicates that empirical rheological index penetration has good correlation to CI or SI. An interesting phenomenon can also be found in Table 4 that CI and SI of each recycling cycle are less than those of the same ageing 


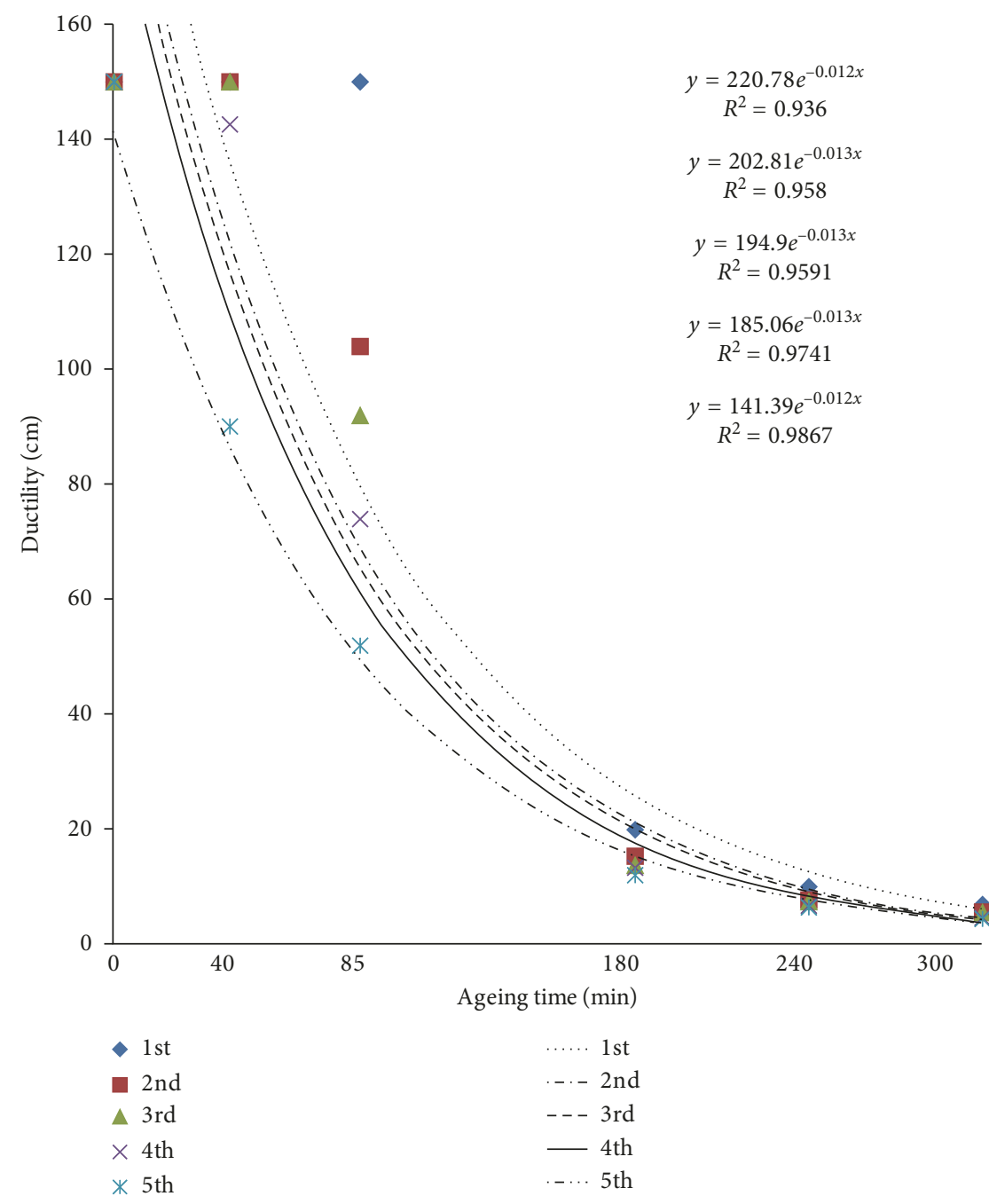

FIGURE 6: Softening point against ageing cycle number for different ageing time periods.

cycle; however, decrease in degree of CI is much more obvious than that of SI (e.g., CI of the first recycling is 0.051 , whereas that of the first ageing cycle is 0.116 , which corresponds to a decrease of $56 \%$; in the same case, SI decreases only $12 \%)$. The mechanism of this phenomenon is to be for further research.

\subsection{Rejuvenator Dosage Analysis and Effect Evaluation of} Asphalt Multicycle Ageing and Recycling. As mentioned in the section of rejuvenator dosage determination, the best rejuvenator content by weight was obtained by comparative tests based on initial estimated value by (2). Optimum rejuvenator contents for each recycling cycle of all five groups (1 5) aged asphalt with different ageing time periods are shown in Table 5.

From results in Table 5, the optimum rejuvenator content increases with the ageing time and the ageing cycle number, indicating that asphalt rejuvenating capability is related with the two factors above. It corresponds to the relationship between empirical rheological indices and ageing time or ageing cycle number. It is the same as the penetration that the maximum change of optimum rejuvenator content for any group asphalt sample occurs between the $3 \mathrm{rd}$ and 4 th ageing cycles, which indicates that penetration is an important empirical rheological index to evaluate asphalt rejuvenating effect.

Currently there are two methods, the macro- and microevaluation, to evaluate asphalt rejuvenating effect [34]. The macroevaluation focuses on performance of recycled asphalt, with evaluation indices such as penetration, softening point, ductility, and viscosity. However, the microevaluation utilizes constituents and molecular weight distribution analysis to evaluate the asphalt rejuvenating effect. Because empirical rheological indices are related to asphalt pavement performance, the macroevaluation is more commonly used in practice. In this study, the two-level monitoring index evaluation system has been established, namely penetration as the main index for partly reflecting asphalt rheological properties and softening point and ductility as the auxiliary indices.

Figures 10-12, respectively, show results of penetration at $25^{\circ} \mathrm{C}$ and softening point and ductility at $15^{\circ} \mathrm{C}$ after each recycling cycle of different ageing time periods. Penetration at $25^{\circ} \mathrm{C}$ after each recycling cycle should be strictly controlled 


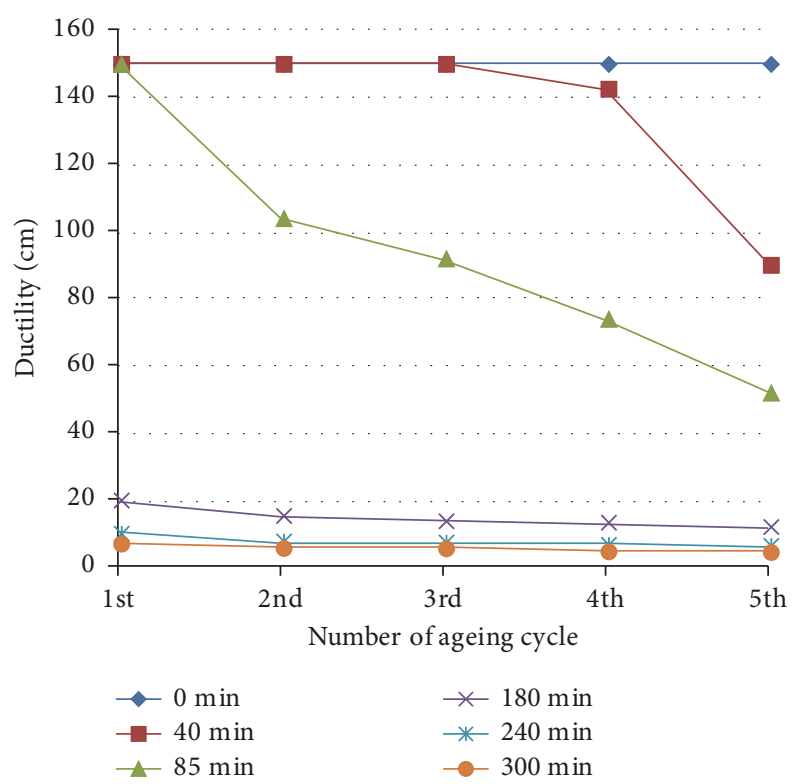

FIgURE 7: Ductility at $15^{\circ} \mathrm{C}$ against ageing cycle number for different ageing time periods.

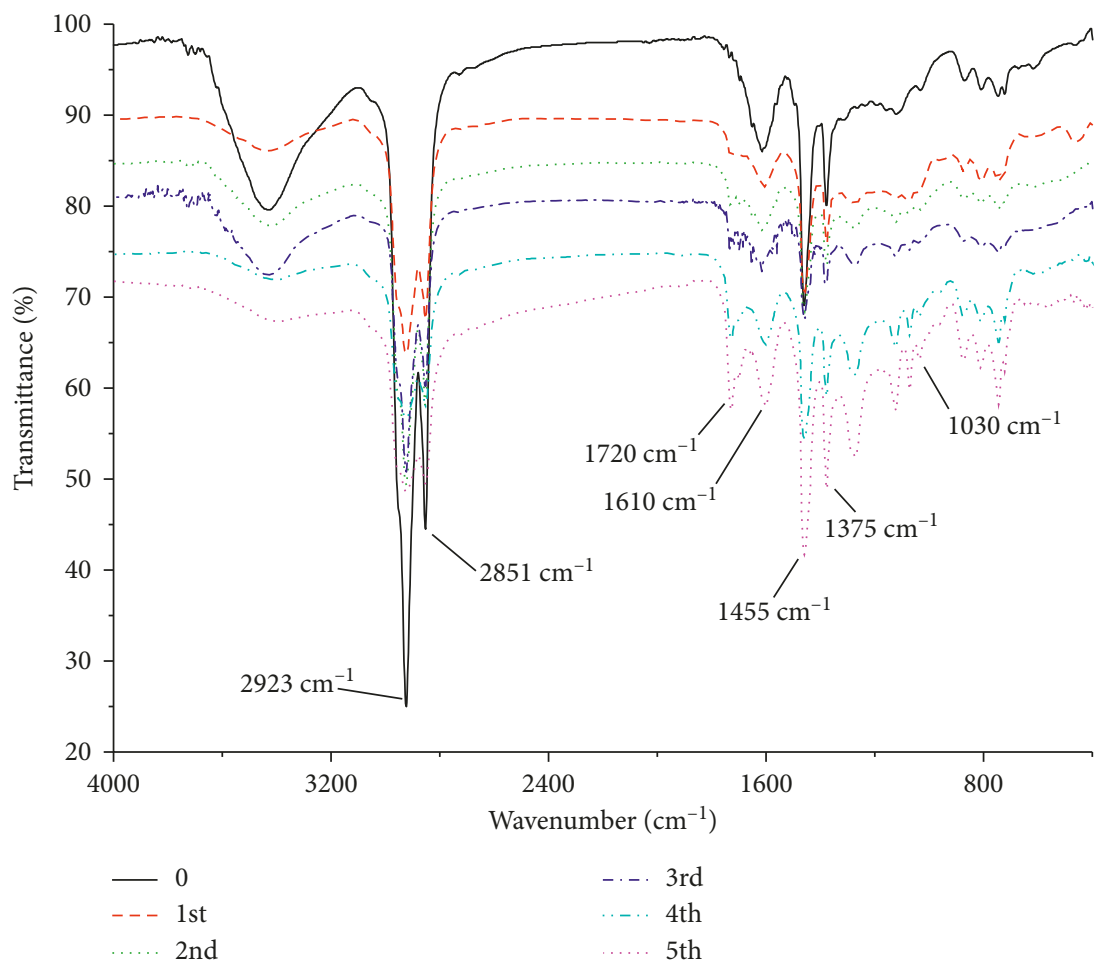

FIGURE 8: Infrared spectra of asphalt in each ageing cycle for $180 \mathrm{~min}$.

at the range between $60(0.1 \mathrm{~mm})$ and $80(0.1 \mathrm{~mm})$ according to present Chinese specifications [22]. Figure 10 shows that penetration values satisfactorily meet the requirement. It is indicated in Figure 11 that all the softening point values of recycled asphalt in each cycle are recovered at the range of $55 \sim 60^{\circ} \mathrm{C}$, completely meeting the demand of over $45^{\circ} \mathrm{C}$ in current Chinese specifications [22]. Figure 12 shows that the ductility values at $15^{\circ} \mathrm{C}$ after the 1 st and 2 nd recycling cycle are restored to the $150 \mathrm{~cm}$ of virgin asphalt. Though the values in the other three cycles for some longer ageing time periods are not restored satisfactorily, the lowest value occurring in the 5th recycling cycle for $300 \mathrm{~min}$ reaches $110 \mathrm{~cm}$ meeting the requirement of over $100 \mathrm{~cm}$ stipulated in related Chinese specifications [22]. 


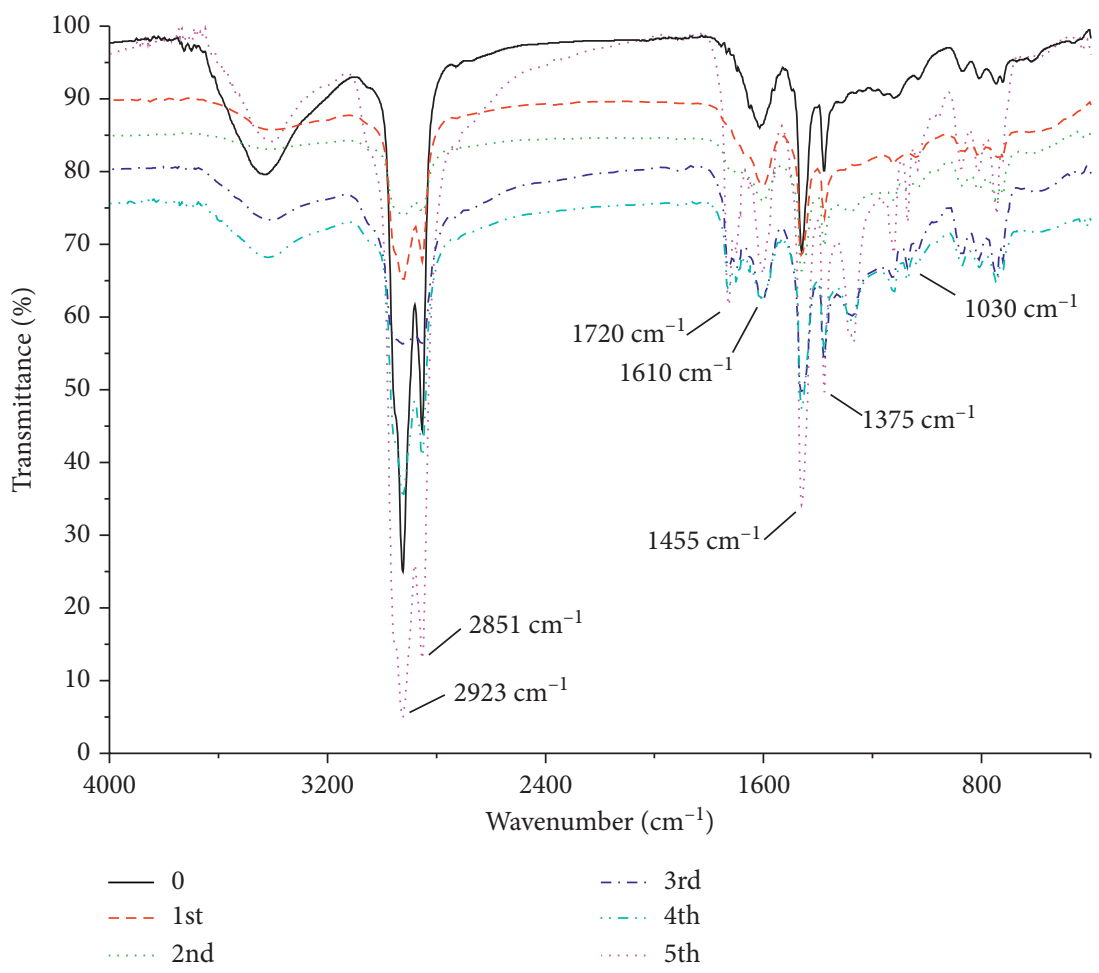

FIGURE 9: Infrared spectra of asphalt in each recycling cycle for $180 \mathrm{~min}$.

TABLE 4: FTIR test CI and SI of virgin asphalt and asphalt after each ageing or recycling cycle for group 3.

\begin{tabular}{lccccccccccc}
\hline \multirow{2}{*}{ Index } & \multirow{2}{*}{ Virgin asphalt } & \multicolumn{4}{c}{ Asphalt after each 180 min ageing cycle } & \multicolumn{4}{c}{ Asphalt after each recycling cycle } \\
& & 1st & 2nd & 3rd & 4th & 5th & 1st & 2nd & 3rd & 4th & 5th \\
\hline CI (-) & 0 & 0.116 & 0.148 & 0.156 & 0.307 & 0.311 & 0.051 & 0.073 & 0.091 & 0.182 \\
SI (-) & 0.043 & 0.065 & 0.071 & 0.082 & 0.162 & 0.171 & 0.057 & 0.063 & 0.070 & 0.126 & 0.145 \\
\hline
\end{tabular}

TABLE 5: Optimum rejuvenator contents for each recycling cycle with different ageing durations (groups 1 5).

\begin{tabular}{lccccccc}
\hline \multirow{2}{*}{ Ageing time (min) } & \multicolumn{4}{c}{ Optimum rejuvenator content by weight (\%) } & Average optimum rejuvenator content of each group \\
& 1st & 2nd & 3rd & 4th & 5 th & (\%) \\
\hline 40 (group1) & 19 & 20 & 21 & 24 & 25 & 31.8 \\
85 (group2) & 29 & 30 & 31 & 34 & 35 & 48.2 \\
180 (group3) & 46 & 46 & 47 & 51 & 51 & 52.2 \\
240 (group4) & 49 & 50 & 51 & 55 & 56 & 55.3 \\
300 (group5) & 53 & 54 & 54 & 57 & 58 & \\
\hline
\end{tabular}

Selecting suitable rejuvenator with the right dosage, it is feasible for asphalt in multicycle ageing and recycling process to be recovered to empirical rheological indices level of virgin one and satisfy the demand stipulated in specifications. The good practical rejuvenating effect verifies effectiveness of rejuvenator dosage determination method.

\section{Conclusions}

This paper presents a study of AH-70 virgin pavement asphalt ageing behavior and rejuvenating possibility in five cycles with repeated ageing and recycling for different ageing time periods. This study is based on RTFOT, empirical rheological tests, IR analysis, rejuvenator dosage comparative tests, and rejuvenating effect macroevaluation system.

Empirical rheological indices analysis indicates that the deterioration degree of the asphalt in the multicycle ageing and recycling process mainly depends on two factors, ageing time and ageing cycle number. With regard to the impact on empirical rheological indices, the former is much more important than the latter, exhibiting an exponential relationship with indices values. For the latter, the maximum decrease of penetration values appears between the 3 rd and 4 th cycles, being consistent with IR quantitative calculation results. 


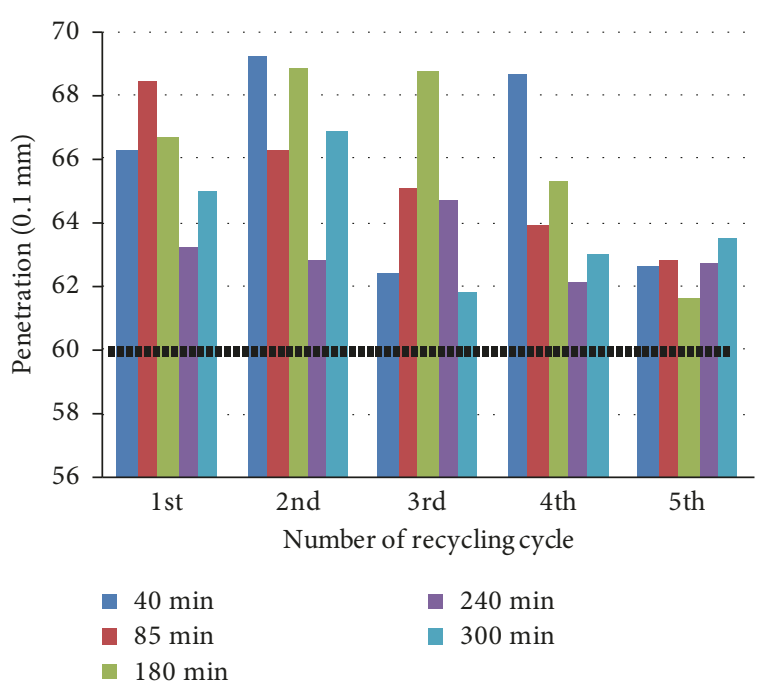

Figure 10: Penetration at $25^{\circ} \mathrm{C}$ after each recycling cycle for different ageing time periods.

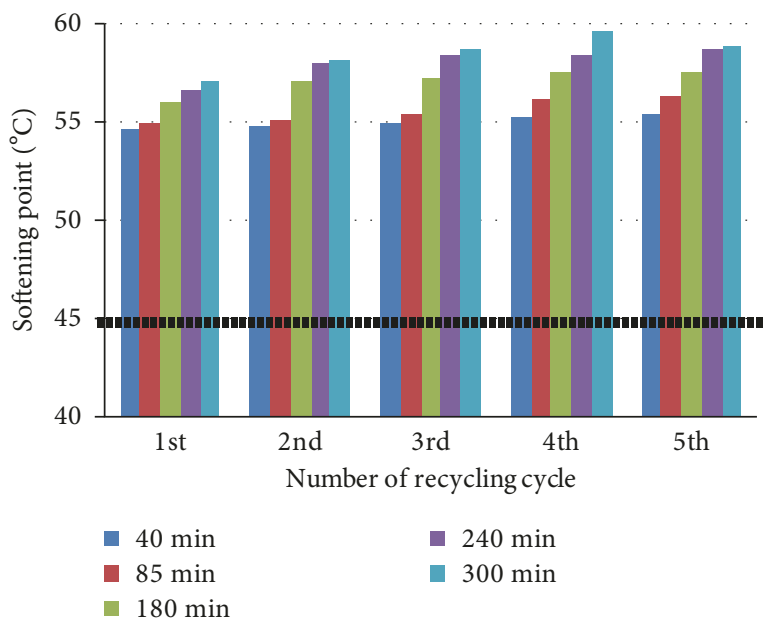

Figure 11: Softening point after each recycling cycle for different ageing time periods.

In IR analysis, appearance of new absorption peaks and intensity increase of some absorption peaks show that polar functional groups are produced and constituents and molecular weight distribution is changed in the multicycle ageing and recycling process. Increase of CI and SI with ageing cycle number shows that some ageing damage is accumulative.

A method of empirical formula combined with comparative tests was adopted to determine the optimum rejuvenator content, which is verified effective by the good practical rejuvenating effect on the multicycle aged asphalt. In the two-level rejuvenating effect macroevaluation system, penetration is the master monitoring index, which is verified being of good correlation to chemical indices. Evaluation results indicate that the asphalt after multicycle ageing and recycling can be restored to the empirical rheological indices level of the virgin asphalt and meets related specifications requirements.

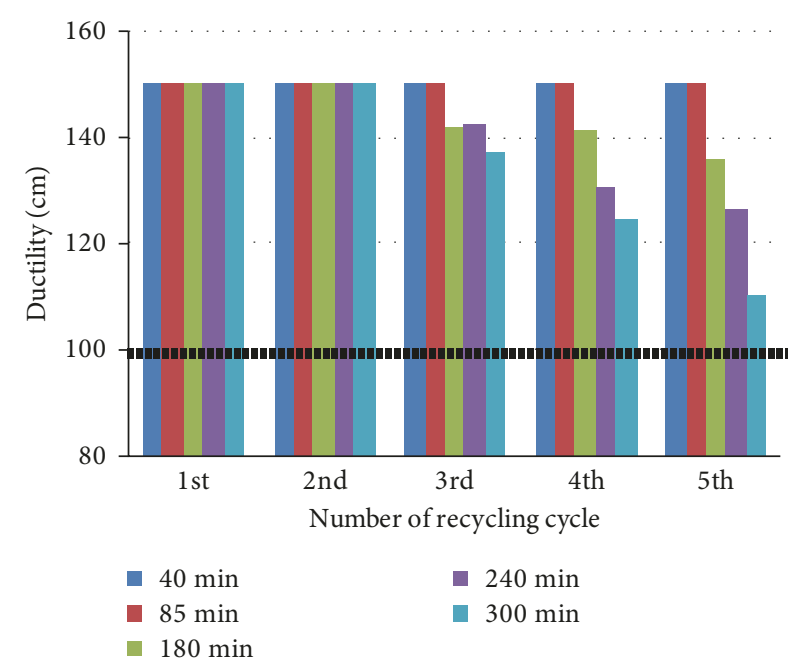

FIgURE 12: Ductility at $15^{\circ} \mathrm{C}$ after each recycling cycle for different ageing time periods.

Selecting suitable rejuvenator with the right content, pavement asphalt multicycle ageing and recycling is feasible. In the first-stage study, related multicycle rejuvenating mechanism is still unknown, for example, obvious difference of rejuvenator recovering effects on CI and SI, which is the main aim in further research.

\section{Conflicts of Interest}

The authors declare that there are no conflicts of interest regarding the publication of this paper.

\section{Acknowledgments}

The authors gratefully acknowledge that this research was financially supported by Open Fund of Key Laboratory of Road Structure and Material of Ministry of Transport (Changsha University of Science \& Technology) (Grant no. kfj150301), the Scientific Research Fund of Hunan Provincial Education Department (Grant no. 15A065), and Hunan Provincial Natural Science Foundation of China(Grant no. 2018JJ2126). Special thanks are expressed to Professor Simon A. M. Hesp for his support and suggestions.

\section{References}

[1] National Asphalt Pavement Association, Asphalt Pavement Industry Survey on Recycled Materials and Warm-Mix Asphalt Usage 2016 (Information Series 138), National Asphalt Pavement Association, Lanham, MD, USA, 2017.

[2] H. M. R. D. Silva, J. R. M. Oliveira, and C. M. G. Jesus, “Are totally recycled hot mix asphalts a sustainable alternative for road paving?," Resources, Conservation and Recycling, vol. 60, pp. 38-48, 2012.

[3] A. A. A. Molenaar, M. Mohajeri, and M. F. C. van de Ven, "Hot recycling in the Netherlands," in Application of Reclaimed Asphalt Pavement and Recycled Asphalt Shingles in Hot-Mix Asphalt (Transportation Research Circular No. E-C188), Transportation Research Board, Washington, DC, USA, 2014. 
[4] K. Kubo, "Recycling in Japan," in Application of Reclaimed Asphalt Pavement and Recycled Asphalt Shingles in Hot-Mix Asphalt (Transportation Research Circular No. E-C188), Transportation Research Board, Washington, DC, USA, 2014.

[5] W. G. Buttlar, E. V. Dave, E. Masad et al., "A micromechanicsbased approach for determining presence and amount of recycled asphalt pavement material in asphalt concrete," Journal of Association of Asphalt Paving Technologists, vol. 74, pp. 829-884, 2005.

[6] W. Guthrie, D. Cooley, and D. Eggett, "Effects of reclaimed asphalt pavement on mechanical properties of base materials," Transportation Research Record: Journal of the Transportation Research Board, vol. 2005, no. 1, pp. 44-52, 2007.

[7] J. C. Petersen, A Review of the Fundamentals of Asphalt Oxidation (Transportation Research Circular No. E-C140), Transportation Research Board, Washington, DC, USA, 2009.

[8] A. Copeland, High Reclaimed Asphalt Pavement Use (No. FHWA-HRT-11-057), Federal Highway Administration, Washington, DC, USA, 2011.

[9] S.-C. Huang, W. Grimes, T. Pauli et al., Ageing Characteristics of RAP Binders-What Types of RAP Binders Suitable for Multiple Recycling? (Technical White Paper Prepared for Federal Highway Administration No. DTFH61-07-D-00005), West Research Institute, Laramie, WY, USA, 2015.

[10] S. Erkens, L. Porot, R. Glaser et al., "Review of asphalt (concrete) ageing tests in the US and Europe," in Proceedings of the 95th Annual Meeting of the Transportation Research Board, Washington, DC, USA, January 2016.

[11] G. D. Peterson, R. R. Davison, C. J. Glover et al., "Effect of composition on asphalt recycling agent performance," Transportation Research Record: Journal of the Transportation Research Board, vol. 1436, pp. 38-46, 1994.

[12] J. Shen, S. Amirkhanian, and B. Tang, "Effects of rejuvenator on performance-based properties of rejuvenated asphalt binder and mixtures," Construction and Building Materials, vol. 21, no. 5, pp. 958-964, 2006.

[13] P. Shirodkar, Y. Mehta, A. Nolan, E. Dubois, D. Reger, and L. McCarthy, "Development of blending chart for different degrees of blending of RAP binder and virgin binder," Resources, Conservation and Recycling, vol. 73, pp. 156-161, 2013.

[14] M. Mohamadafzali, H. Ali, J. A. Musselman et al., "Long-term aging of recycled asphalt binders: a laboratory evaluation based on performance grade tests," in Proceedings of the International Airfield and Highway Pavements Conference 2015, Miami, FL, USA, June 2015.

[15] B. Kalman, Re-Road Summary Report (Re-Road_D7.3, Project ID: 218747), European Community's Seventh Framework Programme, Sweden, 2013.

[16] X. Luo and J. Ji, "Comparison on the anti-ageing capacity of asphalt in two ageing and recycling cycles," in Proceedings of the 11th International Conference of Chinese Transportation Professionals, Nanjing, China, August 2011.

[17] M. Montepara, G. Tebaldi, and E. Romeo, "Comparison on the anti-ageing capacity of asphalt in two ageing and recycling cycles," in Proceedings of the 6th International Conference on Maintenance and Rehabilitation of Pavements and Technological Control, Turin, Italy, July 2009.

[18] P.-L. Li, Z.-Q Zhang, B.-G. Wang et al., "Experimental research on thermo-oxidative aging for simulation of pavement asphalt aging," Journal of Zhengzhou University (Engineering Science), vol. 29, no. 1, pp. 119-123, 2008, in Chinese.

[19] J. M. Shiau, M. Tia, B. E. Ruth et al., "Evaluation of ageing characteristics of asphalts by using TFOT and RTFOT at different temperature levels," Transportation Research Record: Journal of the Transportation Research Board, vol. 1342, pp. 58-66, 1992.

[20] M. Mohajeri, A. A. A. Molenaar, and M. F. C. van de Ven, "Blending of virgin bitumen and RA binder in mixtures with high amounts of RA," in Application Advances in Asphalt Materials-Road and Pavement Construction, Woodhead Publishing, Cambridge, UK, 2015.

[21] M. D. Nazzal, W. Mogawer, A. Austerman, L. A. Qtaish, and S. Kaya, "Multi-scale evaluation of the effect of rejuvenators on the performance of high RAP content mixtures," Construction and Building Materials, vol. 101, pp. 50-56, 2015.

[22] Ministry of Transport, Technical Specifications for Construction of Highway Asphalt Pavements (JTG F40-2004), Ministry of Transport, Beijing, China, 2004, in Chinese.

[23] Ministry of Transport, Technical Specifications for Highway Asphalt Pavements Recycling (JTG F41-2008), Ministry of Transport, Beijing, China, 2008, in Chinese.

[24] American Association of State and Highway Transportation Officials, Standard Method of Test for Effect of Heat and Air on a Moving Film of Asphalt (Rolling Thin-Film Oven Test) (AASHTO T240-13), American Association of State and Highway Transportation Officials, Washington, DC, USA, 2013.

[25] Ministry of Transport, Standard Test Methods of Bitumen and Bituminous Mixtures for Highway Engineering/Asphalt Penetration Experiments (JTG E20-2011/T 0604-2011), Ministry of Transport, Beijing, China, 2011, in Chinese.

[26] Ministry of Transport, Standard Test Methods of Bitumen and Bituminous Mixtures for Highway Engineering/Asphalt Softening Point Experiments (Ball and Ring Testing Method) (JTG E20-2011/T 0606-2011), Ministry of Transport, Beijing, China, 2011, in Chinese.

[27] Ministry of Transport, Standard Test Methods of Bitumen and Bituminous Mixtures for Highway Engineering/Asphalt Ductility Experiments (JTG E20-2011/T 0605-2011), Ministry of Transport, Beijing, China, 2011, in Chinese.

[28] W.-M. Lv and J.-J. Yan, Asphalt Pavements Regeneration Technology, China Communications Press, Beijing, China, 1989, in Chinese.

[29] A. F. Verhasselt and F. S. Choquet, "Comparing field and laboratory ageing of bitumen on a kinetic basis," Transportation Research Record: Journal of the Transportation Research Board, vol. 1391, pp. 30-38, 1993.

[30] M. Liu, K. M. Lunsford, R. R. Davison, C. J. Glover, and J. A. Bullin, "The kinetics of carbonyl formation in asphalt," AIChE Journal, vol. 42, no. 4, pp. 1069-1076, 1996.

[31] L. Pang, L. Lu, S.-P. Wu et al., "Laboratory study on kinetics of ultraviolet radiation ageing of asphalt," in Proceedings of the 2010 C-MRS Annual Meeting, Changsha, China, June 2010, in Chinese.

[32] H. Zhao, K.-J. Liao, and H.-P. Li, "Study on the ageing kinetics of regenerated modified asphalt based on softening point," Chemistry and Adhesion, vol. 33, no. 1, pp. 27-29, 2011, in Chinese.

[33] M. F. Ali and M. N. Siddiqui, "Changes in asphalt chemistry and durability during oxidation and polymer modification," Petroleum Science and Technology, vol. 19, no. 9-10, pp. 1229-1249, 2007.

[34] N. Sabahfar, Effect of Rejuvenating Agent on Aged Reclaimed Asphalt Pavement and Binder Properties, Ph.D. thesis, Kansas State University, Manhattan, KS, USA, 2016. 


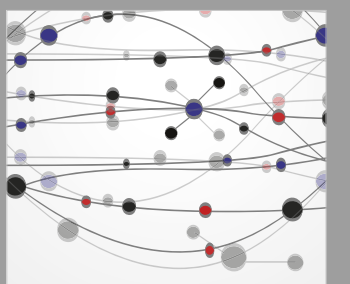

The Scientific World Journal
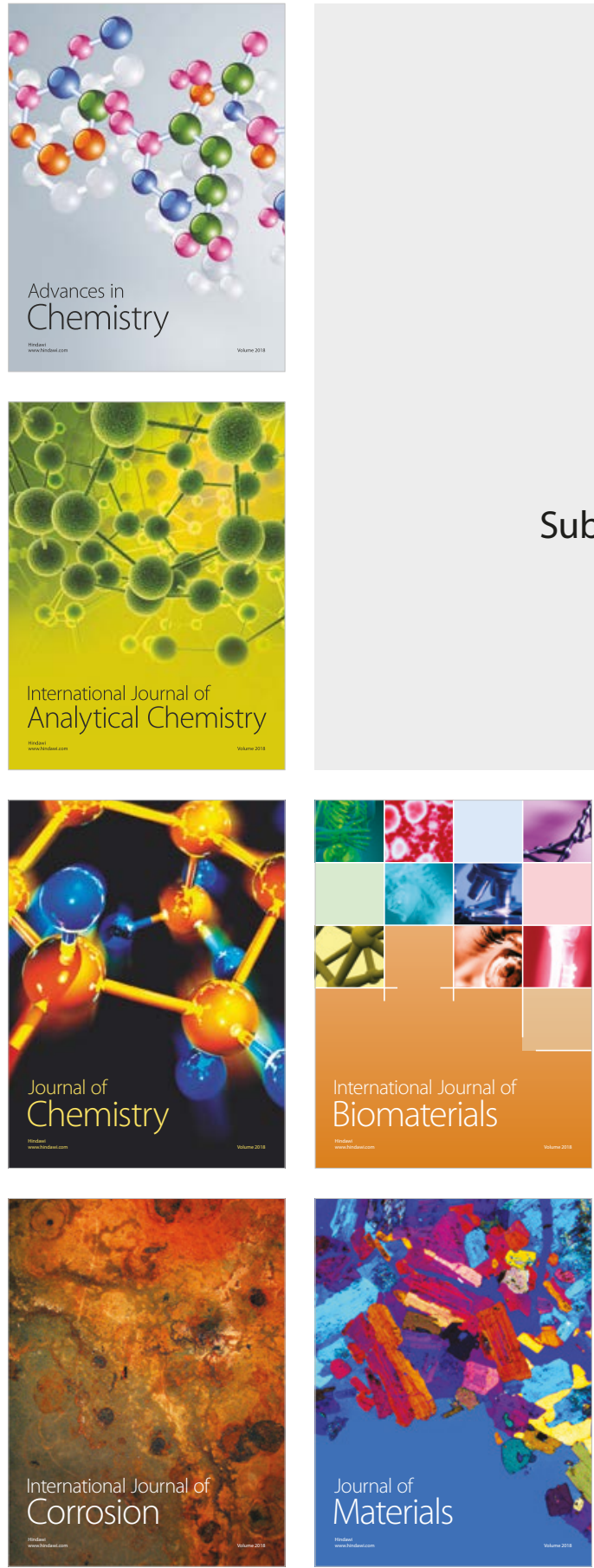

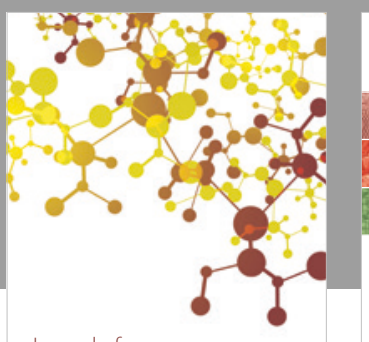

Journal of

Applied Chemistry
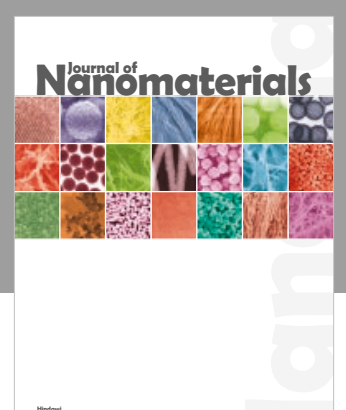

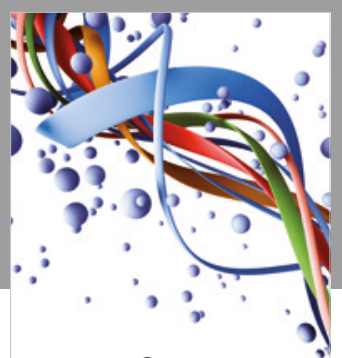

Scientifica

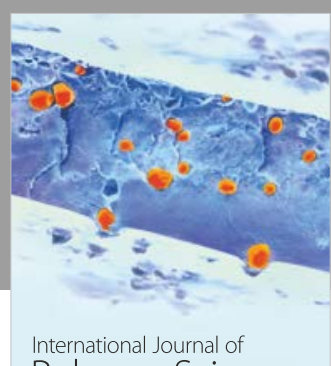

Polymer Science

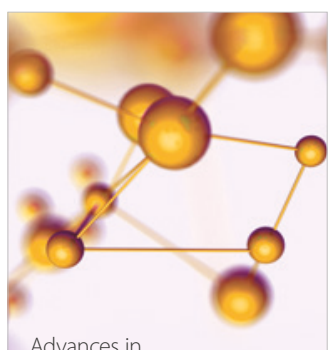

Physical Chemistry
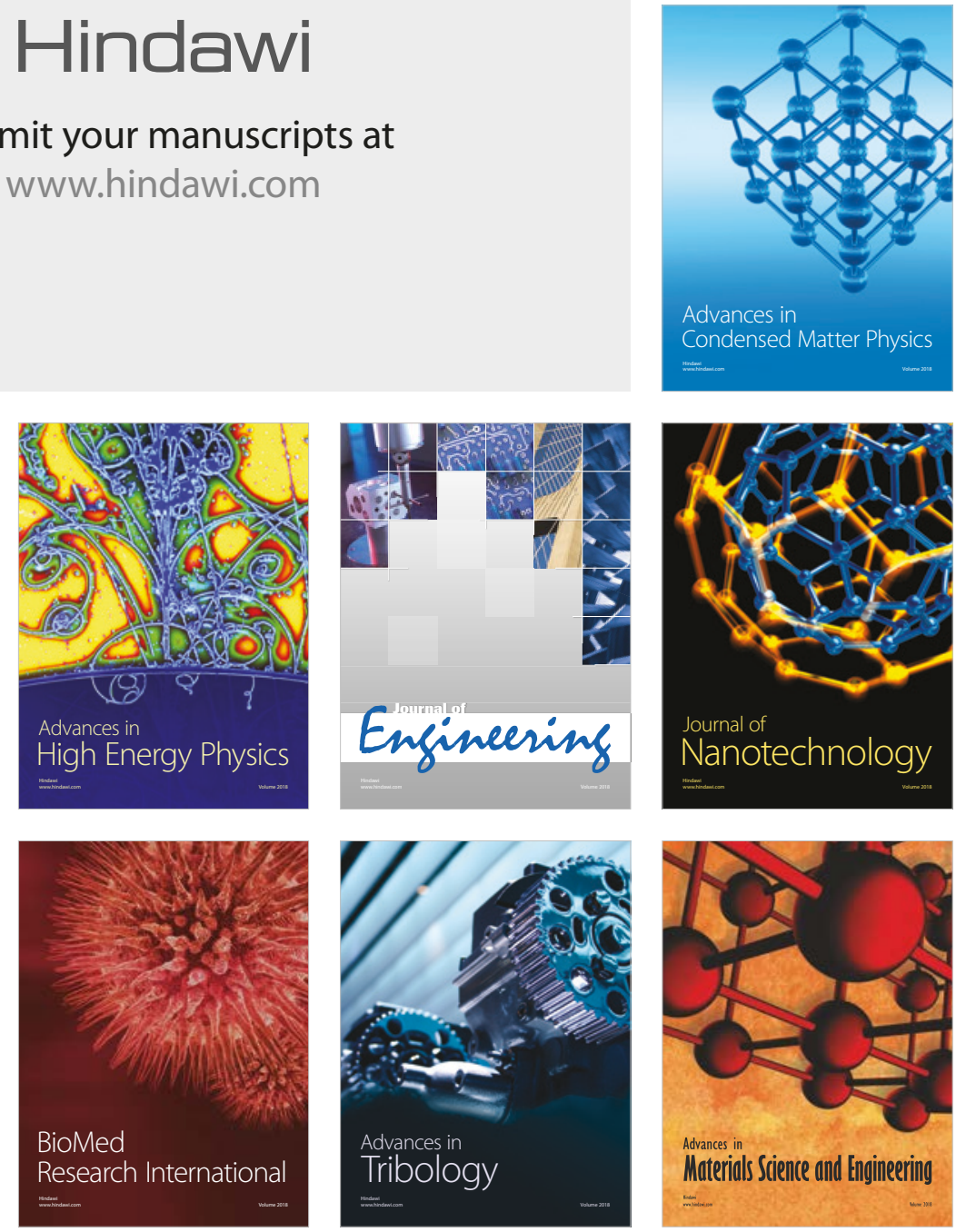